\title{
MỘT SỐ ĐẶC ĐIÊM SINH HỌC CỦA LOÀI CÁ NỤC SỒ DECAPTERUS MARUADSI (TEMMINCK \& SCHLEGEL, 1843) Ở VÙNG BIẼN VỊNH BẮC BỘ
}

\author{
Hoàng Ngọc Sơn, Vũ Việt Hà* \\ Viện Nghiên cúu Hải sản-Bộ Nông nghiệp và Phát triển Nông thôn \\ *E-mail: havuviet@gmail.com
}

Ngày nhận bài: 29-10-2015

TÓM TĂT: Đặc điểm sinh hoc của cá nục sồ Decapterus maruadsi (Temminck \& Schlegel, 1843) đurợc phân tích dụa trên số liệu sinh học nghề cá do dư án điều tra liên hơp Việt - Trung "Đánh giá nguồn lợi hải sản trong vùng đánh cá chung vịnh Bắc Bộ" thu thập trong giai đoạn 2012 - 2013. Hàng tháng, mẫu sinh học được thu thập ngẫu nhiên tù sản lượng khai thác của các độ tàu kéo đáy ở Cát Bà (Hải Phòng) và Lach Hới, Lach Bạng (Thanh Hóa). Trong giai đoạn 2012 - 2013, đã thu thập và phân tích tổng số 7.614 cá thể cá nục sồ. Kết quả nghiên cưu cho thấy chiều dài cá bắt gặp trong sản lương khai thác dao động trong khoảng tù $45-262 \mathrm{~mm}$. Kích cõ̃ trung bình thu được khoảng $166-167 \mathrm{~mm}$. Phương trình sinh truởng Von Bertalanffy của cá nuc sồ có dạng $\left.L_{t}=283,5 \times\left(1-e^{-0,7 \times\left(t-t_{0}\right.}\right)\right)$. Mùa sinh sản của cá nục sồ kéo dài trong khoảng tù̀ tháng 1 đến tháng 4 hàng năm với đỉnh sinh sản ở tháng 3. Chiều dài lần đầu sinh sản của cá cái uớc tính là $160,96 \mathrm{~mm}$ và cá đục là $161,37 \mathrm{~mm}$.

Tù khóa: Decapterus maruadsi, cá nục sồ, vịnh Bắc Bộ, phuoong trình sinh truởng Von Bertalanffy, tần suất chiều dài, mùa sinh sản.

\section{Mở ĐẦU}

Cá nục sồ Depcaterus maruadsi (Temminck \& Schlegel, 1843) là loài cá nổi nhỏ thuộc họ cá khế (Carangidae), phân bố rộng ở vùng biển nhiệt đới, từ phía đông Ấn Độ Dương đến tây Thái Bình Dương tại những vùng nước ấm dọc ven biển Trung Hoa, Việt Nam, Nhật, Malaysia, Philippines, Indonesia. Ở vùng biển Việt Nam, cá nục sồ bắt gặp ở hầu hết các vùng biển, từ vịnh Bắc Bộ cho tới ven biển miền Trung, Đông Nam Bộ và Tây Nam Bộ [6]. Hiện tại giống Decapterus trên thế giới đã phát hiện được 11 loài $[1,2]$, trong đó 4 loài đã được phát hiện tại Việt Nam, gồm Decapterus maruadsi, Decapterus russelli, Decapterus kurroides, Decapterus lajang thì cá nục sồ Decapterus maruadsi là loài có sản lượng cao nhất, chúng thường chiếm tới $10 \%$ sản lượng khai thác của nghề kéo đáy [3]. Trước đây, nhiều công trình nghiên cứu đã được thực hiện, tập trung ở các lĩnh vực về hình thái phân loại, các đặc điểm sinh học của cá nục sồ ở vùng biển Việt Nam, trong đó có thể kể đến các nghiên cứu nổi bật của Lê Tự Cường (1985), Nguyễn Viết Nghĩa (1999), Đào Mạnh Sơn (2005). Tuy nhiên, hầu hết các nghiên cứu đều có thời điểm nghiên cứu khá xa nhau, nghiên cứu chưa đầy đủ và phần lớn dựa trên nguồn số liệu từ một vài chuyến khảo sát đơn lẻ mà không theo hệ thống. Do vậy, việc tiến hành nghiên cứu bổ sung cho đặc điểm $\sinh$ học sinh sản loài cá này là rất cần thiết. Trên cơ sở đó, dựa vào số liệu đã thu thập được từ nghề cá thương phẩm tại hai điểm lên cá trọng điểm là Cát Bà (Hải Phòng) và Lạch Hới, 
Lạch Bạng (Thanh Hóa) bài báo này sẽ công bố kết quả nghiên cứu về một số đặc điểm sinh học của cá nục sồ ở vùng biển vịnh Bắc Bộ.

\section{TÀI LIÊU, VÀ PHƯƠNG PHÁP NGHIÊN CÚU}

\section{Tài liệu nghiên cứu}

Tài liệu sử dụng trong bài viết bao gồm số liệu của 24 chuyến điều tra sinh học nghề cá do dự án Điều tra liên hợp Việt - Trung "Đánh giá nguồn lợi hải sản trong vùng đánh cá chung vịnh Bắc Bộ" thu thập trong giai đoạn 2012 2013.

\section{Phương pháp nghiên cứu}

\section{Phưong pháp thu thập số liệu}

Mẫu sinh học của loài cá nục sồ được thu thập ngẫu nhiên trong sản lượng khai thác của các tàu cá khi về bán sản phẩm ở các cảng cá Cát Bà (Hải Phòng) và Lạch Hới, Lạch Bạng, Ngư Lộc (Thanh Hóa) (hình 1).

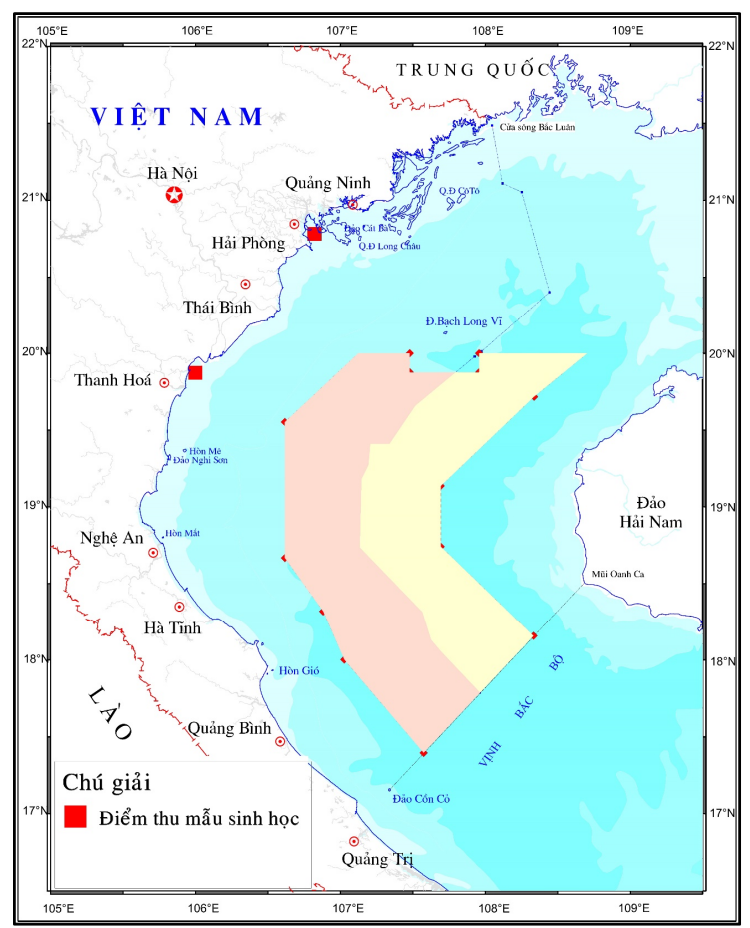

Hình 1. Điểm thu mẫu sinh học cá nục sồ ở vùng biển vịnh Bắc Bộ trong giai đoạn 2012 - 2013

Hàng tháng, khoảng 200 - 300 cá thể cá nục sồ được thu thập và phân tích. Các chỉ tiêu phân tích gồm cân khối lượng (g), đo chiều dài đến chẽ vây đuôi (FL - mm), xác định giới, xác định độ chín muồi sinh dục theo thang 6 bậc của Nikolski (1963) và cân khối lượng tuyến sinh dục [4].

\section{Phương pháp phân tích số liệu}

Tần suất chiều dài của cá nục sồ được phân tích bằng phương pháp thống kê mô tạ. Chiều dài trung bình được xác định dựa trên số liệu tần suất chiều dài thu thập hàng tháng theo hướng dẫn của Jim Fowler (1998) [5]:

$$
\overline{F L}=\frac{1}{n} \sum_{j=1}^{m} f_{1} \times F L_{j}
$$

Trong đó: $\overline{F L}$ là chiều dài đến chẽ vây đuôi trung bình của cá $(\mathrm{mm}) ; \mathrm{FL}_{\mathrm{j}}$ là chiều dài của cá ở nhóm thứ $\mathrm{j}(\mathrm{mm}) ; \mathrm{f}_{\mathrm{j}}$ là số cá thể của nhóm thứ $\mathrm{j} ; \mathrm{n}$ là tổng số cá thể; $\mathrm{m}$ là số nhóm chiều dài.

Phương trình sinh trưởng Von Bertalanffy được xác định dựa trên phân bố tần suất chiều dài hàng tháng và kết quả phân tách thế hệ theo công thức của Pauly và Morgan (1987) [6]:

$$
L_{t}=L_{\infty} \times\left(1-e^{-K *\left(t-t_{0}\right)}\right)
$$

Trong đó: $\mathrm{L}_{\mathrm{t}}$ là chiều dài của cá ở thời điểm $\mathrm{t}$; $\mathrm{L}_{\infty}$ là chiều dài tối đa lý thuyết của cá có thể đạt được; $\mathrm{K}$ là hằng số sinh trưởng; $\mathrm{t}_{0}$ là tuổi lý thuyết giả định mà tại đó cá có chiều dài và khối lượng bằng 0 .

Hệ số thành thục sinh dục là tỉ lệ giữa khối lượng tuyến sinh dục và khối lượng cá bỏ nội quan, tính theo công thức của Bruce J. Barber (2006) [7]:

$$
G S I=\frac{G \mathrm{~W}}{B \mathrm{~W}} \times 100
$$

Trong đó: GW là khối lượng tuyến sinh dục; $\mathrm{BW}$ là khối lượng cá bỏ nội quan.

Chiều dài lần đầu sinh sản $\left(\mathrm{L}_{\mathrm{m} 50}\right)$ được ước tính theo công thức của King (1995) [8]:

$$
P=\frac{1}{\left(1+e^{\left(-k \times\left(F L-L_{m 50}\right)\right)}\right)}
$$


Trong đó: $\mathrm{P}$ là tỉ lệ thành thục sinh dục; $\mathrm{L}_{\mathrm{m} 50}$ là chiều dài đến chẽ vây đuôi của cá; $\mathrm{k}$ là hệ số của phương trình.

\section{KẾT QUẢ NGHIÊN CÚU VÀ THẢO LUẬN Tần suất chiều dài}

Phân bố tần suất chiều dài và kích thước khai thác trung bình của cá nục sồ được trình bày tại hình 2 . Kết quả phân tích cho thấy kích thước khai thác cá nục sồ ở vùng biển vịnh Bắc Bộ có sự biến động nhẹ giữa các tháng khác nhau. Nhìn chung, kích thước trung bình của cá nục sồ thu được trong năm 2013 lớn hơn năm 2012.

Đối với năm 2012, từ tháng 1 đến tháng 3 , quần đàn cá nục sồ chủ yếu là cá có kích thước trung bình trên $150 \mathrm{~mm}$. Cá con xuất hiện chủ yếu ở tháng 4 - tháng 6 . Từ tháng 7 đến tháng 12 , kích cỡ cá tăng dần lên đến $150 \mathrm{~mm}$.

Cá nục sồ ở vùng biển vịnh Bắc Bộ bị khai thác nhiều nhất là nhóm chiều dài $160 \mathrm{~mm}$ $(15,94 \%)$. Nhóm chiều dài có kích thước nhỏ (<120 mm) chiếm tỉ lệ 9,29\%. Nhóm chiều dài có kích thước lớn (>200 mm) chiếm 15,05\%.

Cá nục sồ khai thác được thường tập trung ở nhóm chiều dài nhỏ hơn $120 \mathrm{~mm}$ và từ 170 $180 \mathrm{~mm}$ [3]. Tuy nhiên, do thời điểm nghiên cứu cách xa nhau, sự khác biệt về vùng biển nghiên cứu và đặc biệt trong thời gian gần đây nguồn lợi hải sản bị suy giảm nên có thể quần đàn cá nục sồ đã bị giảm về kích thước lớn nhất bắt gặp.

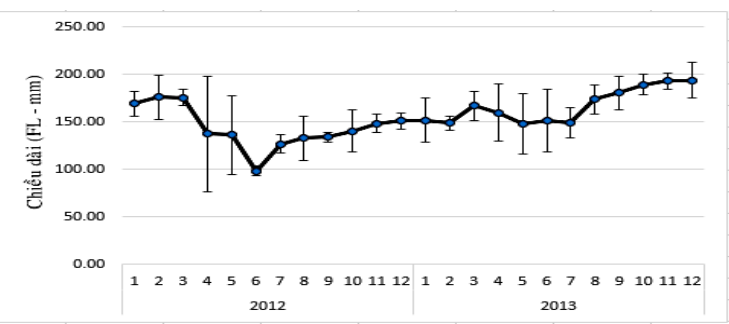

Hình 2. Kích thước trung bình $(\mathrm{mm})$ của cá nục sồ khai thác hàng tháng ở vùng biển vịnh Bắc Bộ trong giai đoạn 2012 - 2013

\section{Tương quan chiều dài và khối lượng}

Cá nục sồ ở vùng biển Bắc Bộ là loài dị sinh trưởng, cơ thể sinh trưởng về khối lượng nhanh hơn sinh trưởng về chiều dài $(b>3)$. Phương trình tương quan chiều dài và khối lượng của loài cá này được xác định cụ thể như sau: $\mathrm{W}=6 \mathrm{E}^{-5} \times \mathrm{L}^{2,6965}$ (chung cho loài, $\mathrm{n}=$ 6.270 cá thể); $\mathrm{W}=6,29 \mathrm{E}^{-5} \times \mathrm{L}^{2,6979}$ (cá đực, $\mathrm{n}=$ 3.254 cá thế); $\mathrm{W}=6,18 \mathrm{E}^{-5} \times \mathrm{L}^{2,6955}$ (cá cái, $\mathrm{n}=$ 3.016 cá thế); $\mathrm{W}=4,60 \mathrm{E}^{-6} \times \mathrm{L}^{3,1975}(1.344$ cá thể). Với độ bao phủ của mẫu thu thập khá rộng (Chiều dài FL dao động từ $45-262 \mathrm{~mm}$ ), và hệ số tương quan rất cao $(\mathrm{R}=0,91 \div 0,99)$ chứng tỏ các phương trình xác định được là đáng tin cậy. Biểu đồ tương quan giữa chiều dài và khối lượng theo giới tính được thể hiện ở hình 3.

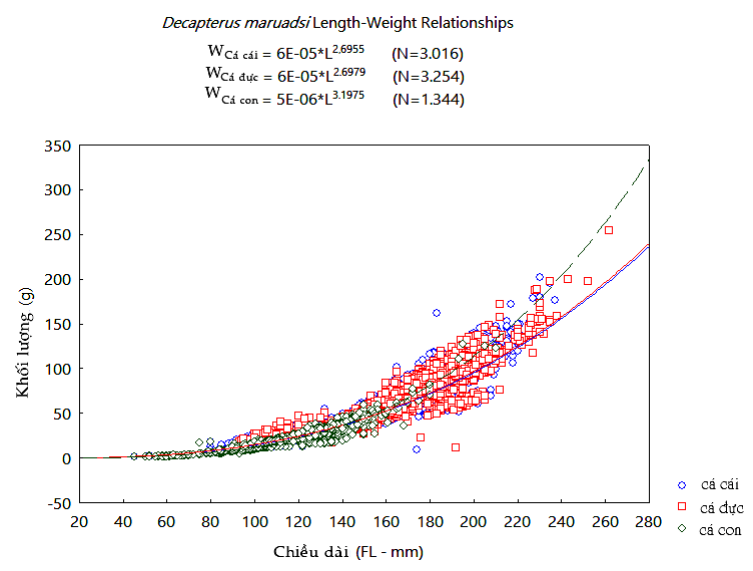

Hình 3. Biểu đồ tương quan chiều dài và khối lượng của cá nục sồ ở vùng biển vịnh Bắc Bộ trong giai đoạn 2012 - 2013

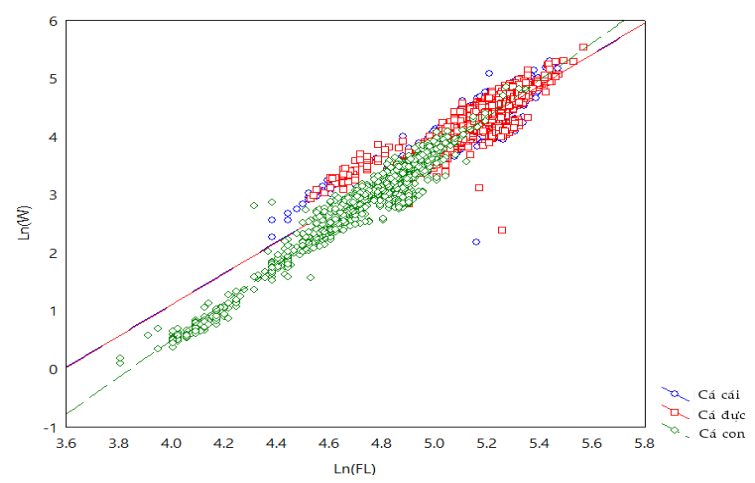

Hình 4. Kết quả phân tích ANOVA so sánh tính tương đồng về chiều dài và khối lượng cá nục sồ ở vùng biển vịnh Bắc Bộ trong giai đoạn 2012 - 2013

Kết quả phân tích ANOVA so sánh tính tương đồng về chiều dài và khối lượng được thể hiện ở hình 4 cho thấy, không có sự khác 
biệt về tương quan chiều dài và khối lượng giữa cá đực và cá cái với mức ý nghĩa $\mathrm{p}>0,05$. Ở giai đoạn cá con, sự khác biệt được thể hiện rõ với mức ý nghĩa $\mathrm{p}<0,01$ khi so sánh với cá trưởng thành (cá cái, cá đực).

Một số kết quả nghiên cứu về tương quan chiều dài - khối lượng của cá nục sồ tại một số vùng biển trong nước và quốc tế được thể hiện qua bảng 1 .

So sánh kết quả nghiên cứu này với kết quả nghiên cứu của Nguyễn Viết Nghĩa tại vùng biển vịnh Bắc Bộ tiến hành năm 1999 có sự sai khác. Do lượng mẫu thu thập khác nhau (7.614 mẫu với 325 mẫu) nên sự khác biệt trong kết quả có thể hiểu được.

Đối với các vùng biển lân cận nội địa như vùng biển Thanh Hóa, có thể thấy hệ số b chung cho loài không chênh lệch quá nhiều. Đối với các vùng biển quốc tế như Trung Quốc, Nhật Bản, vịnh Thái Lan và Philippines, hệ số $\mathrm{b}$ của nghiên cứu này đều cao hơn.

Bảng 1. Hệ số $\mathrm{a}, \mathrm{b}$ của cá nục sồ tại một số vùng biển trong nước và trên thế giới

\begin{tabular}{|c|c|c|c|c|}
\hline Vùng biển & Giới tính & Hệ số a & Hệ số b & Tác giả \\
\hline & Chung & 0,000008 & 3,1059 & \\
\hline \multirow[t]{3}{*}{ Vùng biển vịnh Bắc Bộ } & Đực & 0,000062 & 2,6959 & Nghiên cứu này \\
\hline & Cái & 0,000061 & 2,6955 & \\
\hline & Chung & & 2,830 & \\
\hline \multirow[t]{3}{*}{ Vùng biển vịnh Bắc Bộ } & Đực & & 2,870 & Nguyễn Viết Nghĩa (1999) \\
\hline & Cái & & 2,840 & \\
\hline & Chung & 0,009578 & 3,096 & \\
\hline \multirow[t]{2}{*}{ Vùng biển Thanh Hóa } & Đực & 0,011451 & 3,033 & Trần Văn Cường và Lê Đức Giang (2014) \\
\hline & Cái & 0,009023 & 3,121 & \\
\hline Trung Quốc & Chung & 0,014 & 2,990 & Chen Guobao (2003) \\
\hline Nhật Bản & Chung & 0,018 & 2,900 & Kishida (1972) \\
\hline Vịnh Thái Lan & Chung & 0,0005 & 2,800 & Cheunpan (1981) \\
\hline Visayas (Philippines) & Chung & 0,012 & 3,000 & Federizon, R. (1993) \\
\hline
\end{tabular}

\section{Phương trình sinh trưởng Von Bertalanffy}

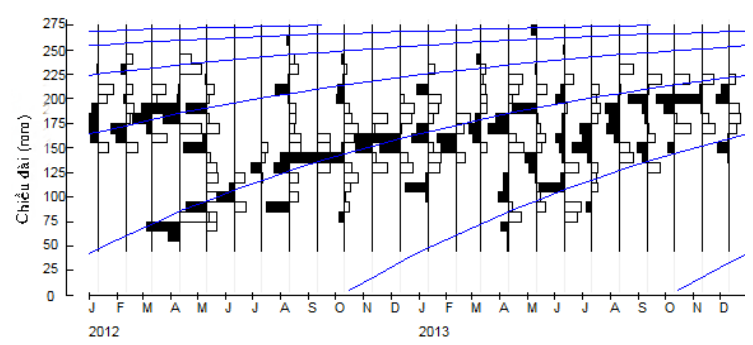

Hình 5. Tần suất chiều dài và đường cong sinh trưởng Von Bertalanffy của cá nục sồ ở vùng biển vịnh Bắc Bộ trong giai đoạn 2012 - 2013

Sử dụng phương pháp ELEFAN I phân tích tần suất chiều dài hàng tháng chung cho cả cá đực và cá cái xác định được phương trình sinh trưởng Von Bertalanffy của cá nục sồ có dạng $L_{t}=283,5 \times\left(1-e^{-0,7 \times\left(t-t_{0}\right)}\right)$ và hệ số sinh trưởng trung bình là $L_{\infty}$. Đối với cá cái, hệ số $L_{\infty}$ và $\mathrm{K}$ trong phương trình sinh trưởng Von Bertalanffy là $L_{\infty}=251 \mathrm{~mm} ; \mathrm{K}=0,85$, cá đực là $L_{\infty}=283,5$ $\mathrm{mm} ; \mathrm{K}=0,7$. Kết quả phân tích cho thấy tốc độ sinh trưởng về chiều dài của cá đực cao hơn so với cá cái (Cá đực: $\phi^{\prime}=4,750$; Cá cái: $\phi^{\prime}=$ 4,732). Đường cong sinh trưởng chung của cá nục sồ được mô tả ở hình 5.

Theo kết quả nghiên cứu này, tham số $\mathrm{K}$ không sai khác nhiều so với nghiên cứu của Chu Tiến Vĩnh và Vũ Việt Hà (2006) ở vùng biển Nghệ An $(K=0,80)$. Điều này cho thấy môi trường sống để cá sinh trưởng gần như nhau.

So sánh $\mathrm{L}_{\infty}$ trong nghiên cứu này với các nghiên cứu ở vùng biển khác nhau trên thế giới (bảng 2) thì cá nục sồ ở vùng biển vịnh Bắc Bộ ở đây không có sự sai khác nhiều so với quần đàn cá ở Biển Đồng [9], quần đàn cá ở biển Java [10] nhưng có sự sai khác với quần đàn ở các vùng biển khác như biển Hoa Đông, Trung Quốc [11], biển Tây Kyushu, Nhật Bản [12]. 


\section{Một số đặc điểm sinh học của loài cá nục sồ ...}

Bảng 2. Các tham số sinh trưởng của cá nục sồ tại một số vùng biển trên thế giới

\begin{tabular}{|c|c|c|c|c|}
\hline Vùng biển & $\mathrm{L}_{\infty}(\mathrm{mm})$ & K(/ năm) & $t_{0}$ (năm) & Tác giả \\
\hline Trung Quốc & 340 & 0,24 & 0,44 & Zhang (1995) \\
\hline Tây Kyushu (Nhật Bản) & 342 & 0,55 & 0,58 & Seiji Ohshimo \& nnk., (2006) \\
\hline Eo Kii & 345 & 0,51 & 0,37 & Takeda (1981) \\
\hline Biển Đông & 243 & 0,32 & 0,89 & Nguyễn Phi Đính (1980) \\
\hline Biển Hoa Đông (Trung Quốc) & 361 & 0,28 & 1,85 & Zhu et và nnk., (1987) \\
\hline Java Sea (Indonesia) & $\begin{array}{l}289 \\
270\end{array}$ & $\begin{array}{l}0,98 \\
0,95\end{array}$ & - & Dwiponggo \& nnk., ( 1986) \\
\hline Burias Pass (Philippines) & 227 & 0,82 & - & Corpuz \& nnk., (1985) \\
\hline Samar Sea (Philippines) & 236 & 0,81 & - & Chu Tiến Vĩnh (2006) \\
\hline Biển Nghệ An & 324 & 0,80 & - & Boonraksa, V. (1987) \\
\hline
\end{tabular}

\section{Tỷ lệ đụ̣c cái}

Biến động tỉ lệ đực cái trong quần thể cá nục sồ ở vùng biển vịnh Bắc Bộ được trình bày ở hình 6. Trong năm 2012 và 2013, tỉ lệ giới trong quần thể có sự tác động theo các chiều hướng khác nhau.

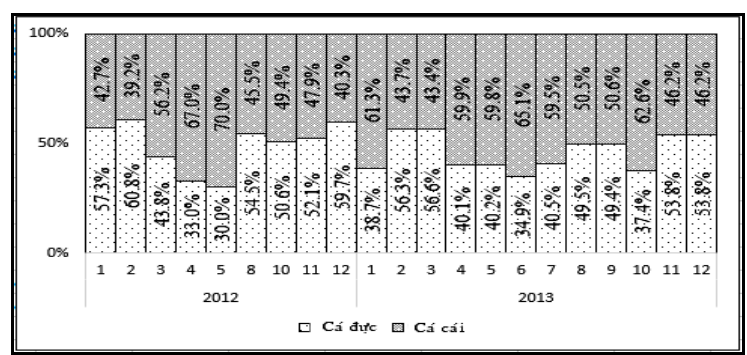

Hình 6. Biểu đồ tỉ lệ đực/cái hàng tháng trong quần thể cá nục sồ ở vùng biển vịnh Bắc Bộ trong giai đoạn 2012 - 2013

Kết quả điều tra cho thấy, trong năm 2012, cá đực chiếm ưu thế ở hầu hết các tháng trong năm với tỉ lệ cao nhất vào tháng $2(60,8 \%)$. Cá cái chiếm tỉ lệ trội ở tháng 3,4 và 5 . Trong đó, tháng 5 cá nục sồ cái chiếm tỉ lệ cao nhất $(70 \%)$. Trong tháng 6 , tháng 7 và tháng $9 / 2012$, toàn bộ cá nục sồ bắt gặp trong mẫu thuộc nhóm cá con, chưa phân định được giới.

Ở năm 2013, cái chiếm ưu thế tại 8/12 tháng trong năm, cụ thể là các tháng 1, 3-9. Trong đó tỉ lệ cao nhất đạt được là ở tháng 6 với $65,1 \%$, thấp nhất ở tháng 8 với $50,5 \%$. Đực chỉ chiếm tỉ lệ trội vào tháng $2,3,11,12$. Trong đó tỉ lệ cao nhất đạt được là ở tháng $2(59,7 \%)$, tỉ lệ thấp nhất đạt được là $53,8 \%$ rơi vào các tháng 11 và 12 .

Nhìn chung, cá đực có xu hướng trội hơn cá cái với tỷ lệ đực cái của quần thể là 1,08:1,00.
Cấu trúc giới tính có sự biến động khác nhau theo tháng. Vào mùa sinh sản, cá cái trội hơn cá đực, với tî̉ lệ đực cái thu được là $0,90: 1,00$.

Trong kết quả nghiên cứu trước đây của Nguyễn Viết Nghĩa (1999), tỉ lệ đực cái thu được là $1: 1$, có sự khác biệt so với nghiên cứu này. Tuy nhiên, kết quả thu được phụ thuộc vào nhiều yếu tố trong đó khu vực tiến hành khảo sát và thời điểm thu mẫu có tính quyết định cao, do vậy sự khác nhau về kết quả trong các nghiên cứu là hoàn toàn có thể.

\section{Biến động tỉ lệ các giai đoạn thành thục sinh dục}

Biến động tỉ lệ các giai đoạn thành thục sinh dục hàng tháng của cá nục sồ ở vùng biển vịnh Bắc Bộ được thể hiện qua hình 7 .

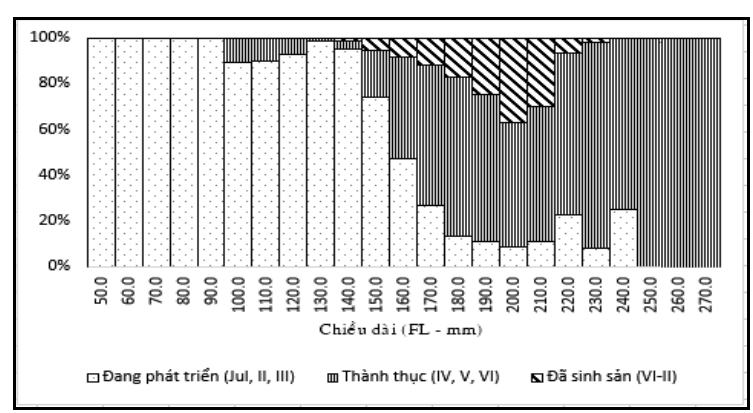

Hình 7. Biến động tỉ lệ các giai đoạn thành thục tuyến sinh dục theo kích cỡ chiều dài trong quần thể cá nục sồ ở vùng biển vịnh Bắc Bộ trong giai đoạn 2012 - 2013

Kết quả phân tích cho thấy, trong năm 2012, cá nục sồ chủ yếu thành thục trong khoảng tháng 1 đến tháng 4 . Trong tháng 3 tỉ lệ cá thành thục sinh dục đạt $100 \%$ cho thấy, đây có thể là đỉnh sinh sản của cá nục sồ. Các mẫu 
quan sát được đang trong giai đoạn còn non (Juvenile) xuất hiện từ tháng 4 cho tới tháng 12 , trong đó chiếm tỉ lệ cao trong khoảng từ tháng 6 tới tháng 9, với tỉ lệ đạt gần như tuyệt đối $(100 \%)$ trong các tháng 6,7 và 9 . Cá ở giai đoạn đang phát triển xuất hiện rải rác tại các tháng trong năm, tuy nhiên tập trung nhiều tại các tháng 10, 11, 12.

Ở năm 2013, tỉ lệ cá thành thục sinh dục hiện diện ở hầu hết các tháng trong năm, tuy nhiên chiếm ưu thế ở các tháng $1-4$ và tháng 10 - 12; Trong đó tháng 3, 4 là cao nhất với tỉ lệ trên $80 \%$. Cá nục sồ trong giai đoạn đang phát triển hiện diện ở hầu hết các tháng trong năm, trong đó cao nhất là tháng 7 (trên $80 \%$ ). Cá trong giai đoạn đã sinh sản quan sát được ở hầu hết các tháng trong năm, đạt cao nhất vào tháng 9 với tỉ lệ 86,6\%.

Biến động tỉ lệ các giai đoạn thành thục tuyến sinh dục của cá theo các nhóm chiều dài được thể hiện trong hình 8 . Kết quả nghiên cứu cho thấy, cá con tập trung chủ yếu ở mức chiều dài từ $50 \mathrm{~mm}$ đến $150 \mathrm{~mm}$. Rất ít cá thể cá con đạt tới kích cỡ $160 \mathrm{~mm}$. Cá thuộc giai đoạn đang phát triển thường dao động từ mức chiều dài 90 đến $260 \mathrm{~mm}$. Chiều dài nhóm cá thuộc giai đoạn thành thục sinh dục chủ yếu từ 150 $250 \mathrm{~mm}$, đặc biệt là $250 \mathrm{~mm}$. Cá đã sinh sản có kích cỡ dao động từ $140-240 \mathrm{~mm}$. Kết quả nghiên cứu cũng cho thấy, toàn bộ cá có chiều dài từ $260-270 \mathrm{~mm}$ thu được đều đã sinh sản.

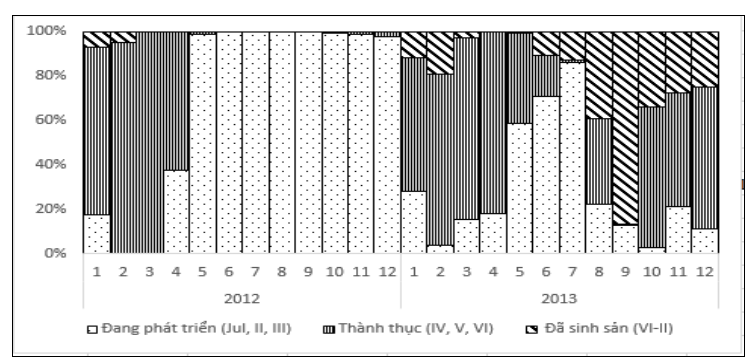

Hình 8. Biến động tỉ lệ các giai đoạn thành thục tuyến sinh dục hàng tháng trong quần thể cá nục sồ ở vùng biển vịnh Bắc Bộ trong giai đoạn 2012 - 2013

Theo nghiên cứu này, cá thể nhỏ nhất thành thục sinh dục là $100 \mathrm{~mm}$, nhỏ hơn so với nghiên cứu về cá nục sồ tại vùng biển Thanh Hóa [2], vịnh Bắc Bộ, vùng biển Nam Bộ [13].

\section{Hệ số thành thục sinh dục}

Hình 9 thể hiện biến động hệ số thành thục sinh dục hàng tháng của cá nục sồ ở vùng biển vịnh Bắc Bộ trong năm 2012 và 2013.

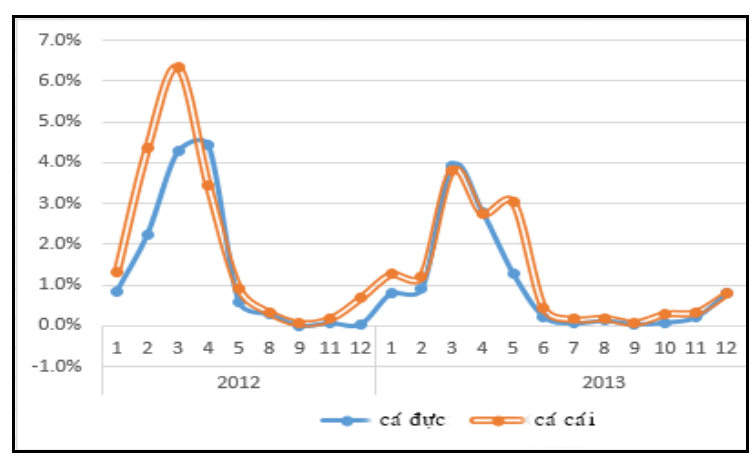

Hình 9. Biến động hệ số thành thục sinh dục của cá nục sồ theo tháng/năm ở vùng biển vịnh Bắc Bộ trong giai đoạn 2012 - 2013

Trong năm 2012, hệ số thành thục sinh dục của cá nục sồ bắt đầu tăng từ tháng 1 , đạt đỉnh vào tháng 3,4 sau đó giảm dần. Cá cái có hệ số thành thục sinh dục cao nhất vào tháng 3 $(6,3 \%)$. Cá đực có hệ số thành thục sinh dục đạt cực đại vào tháng $4(3,5 \%)$. Các tháng từ tháng 5 tới tháng 11 , hệ số thành thục sinh dục thường dao động dưới $0,5 \%$. Tháng 12 là lúc hệ số thành thục sinh dục bắt đầu tăng.

Năm 2013, cá cái có hệ số thành thục sinh dục đạt đỉnh 2 lần: đỉnh chính rơi vào tháng 3 , đỉnh phụ vào tháng 5 . Cá đực có hệ số thành thục sinh dục đạt đỉnh vào tháng 3 , đồng pha với cá cái. Bắt đầu từ tháng 6 , hệ số thành thục sinh dục của cả cá đực và cá cái giảm mạnh, chỉ còn dao động dưới $0,5 \%$, đến tháng 12 thì bắt đầu tăng lên trở lại. Biến động GSI của cá nục sồ cái trong năm 2013 gồm 2 đỉnh liền nhau chứng tỏ cá có hai đợt sinh sản rộ trong mùa sinh sản, đợt sinh sản thứ hai bắt đầu sau đợt sinh sản thứ nhất khoảng một tháng.

\section{Chiều dài lần đầu $\sinh \operatorname{sản}\left(\mathrm{L}_{\mathrm{m} 50}\right)$}

Kết quả ước tính chiều dài lần đầu sinh sản $\left(\mathrm{L}_{\mathrm{m} 50}\right)$ của cá nục sồ ở vùng biển vịnh Bắc Bộ được xác định là $160,96 \mathrm{~mm}$ đối với cá cái và 161,37 mm đối với cá đực. Biểu đồ thể hiện sự tương quan giữa tỉ lệ thành thục và chiều dài của cá nục sồ được trình bày qua hình 10 . 


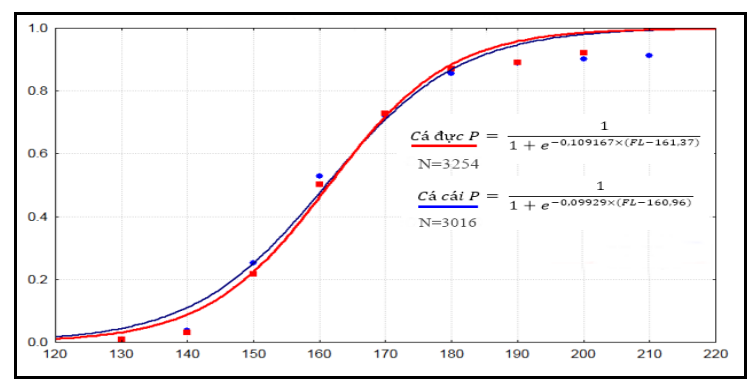

Hình 10. Biểu đồ tương quan tỉ lệ thành thục sinh dục và chiều dài của cá nục sổ ở vùng biển vịnh Bắc Bộ trong giai đoạn 2012 - 2013

So sánh với ước tính cho quần đàn cá nục sồ ở vùng biển Việt Nam của Chu Tiến Vĩnh (2003 - 2006) thì giá trị này nhỏ hơn (bảng 3). Ngoài ra, chiều dài thành thục $\mathrm{L}_{\mathrm{m} 50}$ của cá đực và cá cái cao hơn so với nhóm chiều dài bị khai thác nhiều nhất $(160 \mathrm{~mm})$. Từ hai cơ sở trên trên, có thể kết luận rằng nguồn lợi cá bố mẹ đang bị ảnh hưởng bởi áp lực khai thác cao. Điều này có thể giải thích như sau: Khi áp lực khai thác tăng cao, quá trình bổ sung quần đàn sẽ phải đẩy nhanh lên để kịp thích nghi với môi trường, khiến cho quá trình thành thục sinh dục xảy ra sớm hơn ở các cá thể nhỏ, dẫn tới chiểu dài lần đầu sinh sản bị giảm xuống. Trong thời gian tới, nếu chúng ta không có biện pháp bảo vệ và khai thác một cách hợp lý thì nó sẽ gây sự ảnh hưởng xấu tới sự phát triển nguồn lợi của loài này ở vùng biển vịnh Bắc Bộ.

Bảng 3. Kích cỡ lần đầu sinh sản của cá nục sồ tại một số vùng biển thuộc Việt Nam

\begin{tabular}{lccc}
\hline \multicolumn{1}{c}{ Vùng biển } & Giới tính & & $\mathrm{L}_{\mathrm{m} 50}(\mathrm{~mm})$ \\
Nghệ An & Đực & & $260 \mathrm{~mm}$ \\
& Cái & & $234 \mathrm{~mm}$ \\
Bình Thuận & Đực & & $213 \mathrm{~mm}$ \\
Vịnh Bắc Bộ & Cái & & $188 \mathrm{~mm}$ \\
(Nghiên cứu này) & Đực & & $161,37 \mathrm{~mm}$ \\
\hline
\end{tabular}

\section{Mùa sinh sản}

Mùa sinh sản của cá được xác định dựa trên sự phân tích biến động giá trị GSI và tỉ lệ cá thành thục sinh dục hàng tháng.

Trong nghiên cứu này, kết quả phân tích cho thấy GSI của cá nục sồ cái và cá nục sồ đực cao ở các tháng 1 đến tháng 4 hàng năm, trong đó cá nục sồ cái có 1 đỉnh vào tháng 3 năm 2012 và 2 đỉnh vào tháng 3 và 5 năm 2013; cá nục sồ đực có 1 đỉnh vào tháng 4 năm 2012 và một đỉnh vào tháng 3 năm 2013 (hình 9). Cá thành thục sinh dục tập trung vào tháng 1 đến tháng 4 , cao nhất vào tháng 3 trong 2 năm 2012 - 2013 (hình 8).

Như vậy, có thể nói rằng, mùa sinh sản của cá nục sồ diễn ra trong khoảng từ tháng 1 đến tháng 4 hàng năm. Trong mùa sinh sản cá nục sồ sinh sản mạnh nhất vào tháng 3 .

Những nghiên cứu về đặc điểm sinh học sinh sản của cá nục sồ ở vùng biển Việt Nam cho thấy, cá nục sồ sinh sản rải rác trong năm nhưng đỉnh sinh sản khác nhau giữa các vùng biển. Lê Tự Cường (1985) đã chỉ ra sự khác biệt về mùa vụ sinh sản của cá nục sồ theo các vùng biển, cụ thể như sau: Ở vùng biển phía nam, cá nục sồ có khả năng đẻ hai lần trong một năm. Mùa đẻ chính từ tháng 4 đến tháng 9 , đẻ rộ nhất vào các tháng $6-7$. Mùa đẻ phụ từ tháng 10 đến tháng 3 , đẻ rộ vào các tháng $1-2$. Ở vịnh Bắc Bộ, mùa đẻ của cá nục sồ kéo dài từ tháng 3 đến tháng 9 và đẻ rộ nhất vào các tháng $5,6,7$. Năm 1991, Nguyễn Phi Đính đưa ra nhận định rằng cá nục sồ có mùa sinh sản từ tháng 1 đến tháng 8 , đẻ rộ vào tháng 2 , tháng 4 ở vịnh Bắc Bộ; ở Nghệ An và Thanh Hóa, mùa đẻ kéo dài từ tháng 3 đến tháng 4 , đẻ rộ vào tháng 4 [14].

Nguyễn Viết Nghĩa (1999) chỉ ra rằng, cá nục sổ ở biển Việt Nam đẻ rải rác quanh năm với 2 thời điểm đẻ rộ vào tháng 3 , tháng 4 và tháng 7 , tháng 8 . Theo báo cáo tông kết điều tra liên hợp Việt - Trung đánh giá nguồn lợi hải sản trong vùng đánh cá chung vịnh Bắc Bộ giai đoạn I (2006 - 2007), mùa vụ sinh sản của cá nục sồ khu vực giữa vịnh Bắc Bộ được nhận định là vào khoảng thời gian từ tháng 1 đến tháng 4 . Gần đây nhất, Lê Đức Giang (2014) khi tiến hành nghiên cứu cơ sở khoa học về bảo vệ nguồn lợi cá ở vùng biển tỉnh Thanh Hóa đã kết luận mùa sinh sản cá nục sồ ở vùng biển tỉnh Thanh Hóa kéo dài từ tháng 1 đến tháng 5 hàng năm. Trong mùa sinh sản, cá nục sồ chia làm hai đợt. Đợt sinh sản đầu diễn ra trong tháng 2 hoặc tháng 3 hàng năm, đợt thứ hai rơi vào tháng 4 hoặc tháng 5 [13]. Như vậy, kết quả này hoàn toàn phù hợp với những nghiên cứu trước đây.

\section{KẾT LUẬN}


Chiều dài bắt gặp của cá nục sồ ở vùng biển vịnh Bắc Bộ dao động khoảng 45-262 mm, trong đó tập trung ở nhóm chiều dài 170-180 mm.

Cá nục sồ là loài dị sinh trưởng. Phương trình tương quan chiều dài và khối lượng của loài cái này là $\mathrm{W}=6 \mathrm{E}^{-5} \times \mathrm{L}^{2,6965}$ (chung cho loài, $\mathrm{n}=6.270$ cá thể); $\mathrm{W}=6,29 \mathrm{E}^{-5} \times \mathrm{L}^{2,6979}$ (cá đực, $\mathrm{n}=3.254$ cá thể); $\mathrm{W}=6,18 \mathrm{E}^{-5} \times \mathrm{L}^{2,6955}$ (cá cái, $\mathrm{n}=3.016$ cá thề); $\mathrm{W}=4,60 \mathrm{E}^{-6} \times \mathrm{L}^{3,1975}$ (1.344 cá thể). Có sự khác biệt về tương quan sinh trưởng chiều dài và khối lượng giữa cá con và cá trưởng thành nhưng không có sự khác biệt giữa đực và cái.

Phương trình sinh trưởng cá nục sồ có dạng $L_{t}=283,5 \times\left(1-e^{-0,7 \times\left(t-t_{0}\right)}\right)$ với hệ số sinh trưởng trung bình là $\phi^{\prime}=4,750$. Chiều dài tối đa theo lý thuyết ước tính là $251 \mathrm{~mm}$ đối với cá cái và 283,5 mm đối với cá đực; hệ số $\mathrm{K}$ của cá cái đạt 0,85 và cá đực đạt 0,7 ; hệ số sinh trưởng trung bình của cá cái là $\phi^{\prime}=4,732$ và cá đực là $\phi^{\prime}=4,750$.

Cá đực có $x u$ hướng trội hơn cá cái với tỷ lệ đực cái của quần thể là 1,08:1,00. Cấu trúc giới tính có sự biển động khác nhau theo tháng. Vào mùa sinh sản, cá cái trội hơn cá đực, với tỉ lệ đực cái thu được là 0,90:1,00.

Chiều dài nhỏ nhất bắt gặp cá thành thục sinh dục là $100 \mathrm{~mm}$. Chiều dài lần đầu sinh sản là $160,96 \mathrm{~mm}$ đối với cá cái và $161,37 \mathrm{~mm}$ đối với cá đực. Tỷ lệ thành thục sinh dục đạt $100 \%$ ở cá có chiều dài lớn hơn hoặc bằng $250 \mathrm{~mm}$.

Mùa sinh sản của cá nục sồ kéo dài trong khoảng từ tháng 1 đến tháng 4 hàng năm. Cá sinh sản mạnh nhất vào tháng 3 .

\section{TÀI LIỆU THAM KHẢO}

1. Froese, R., and Pauly, D., 2013. Species of Decapterus, Fishbase.org.

2. Kimura, S., Katahira, K., and Kuriiwa, K., 2013. The red-fin Decapterus group (Perciformes: Carangidae) with the description of a new species, Decapterus smithvanizi. Ichthyological Research, 60(4): 363-379.

3. Chu Tiến Vĩnh, Bùi Đình Chung và Nguyễn Phi Đính, 1998. Đặc điểm sinh học của một số loài cá nồi di cư thuộc giống cá nục (Decapterus), cá bạc má (Rastrelliger) và cá ngừ ở vùng biển Việt
Nam. Tuyển tập các công trình nghiên cứu nghề Cá biển. Tập 1. Nxb. Nông Nghiệp. Tr. 132-141.

4. Nikolsky, G. V., 1963. Ecology of fishes. In Ecology of fishes. Academic Press.

5. Fowler, J., Cohen, L., and Jarvis, P., 1998. Practical Statistics for Field Biology. John Wiley \& Sons Ltd. Chichester. 259 pp.

6. Pauly, D., and Morgan, G. R. (Eds.)., 1987. Length-based methods in fisheries research (Vol. 13). WorldFish.

7. Barber, B. J., and Blake, N. J., 2006. Reproductive physiology. Developments in aquaculture and fisheries science, 35, 357-416.

8. King, M., 1995. Fisheries biology, assessment and management. Blackwell Publishing Ltd. 400 pp.

9. Nguyễn Phi Đính, 1998. Sinh trưởng cá nục sồ Decapterus maruadsi ở vùng biển Đông Việt Nam. Tuyển tập nghiên cứu biển. Viện Nghiên cứu Biển. Tr. 209-226.

10. Dwiponggo, A., Hariati, T., and Banon, S., 1986. Growth, mortality and recruitment of commercially important fishes and penaeid shrimps in Indonesian waters. ICLARM contribution (ISSN 0115-5547, (351).

11. Delin, Z., Haitang, S., Zhili, B., and Zujie, $W$., 1984. A study on mackerel and round scadfishing ground off zhejiang coastin the Summer-Autumn season [J]. Marine Science Bulletin, 2, 007.

12. Ohshimo, S., Yoda, M., Itasaka, N., Morinaga, N., and Ichimaru, T., 2006. Age, growth and reproductive characteristics of round scad Decapterus maruadsi in the waters off west Kyushu, the East China Sea. Fisheries Science, 72(4): 855-859.

13. Lê Đức Giang, Vũ Việt Hà, Trần Văn Cường, 2014. Nghiên cứu xác định mùa sinh sản của một số loài cá biển ở vùng biển Thanh Hóa và lân cận. Tạp chí Nông nghiệp và Phát triển Nông thôn, 21, 90-95.

14. Nguyễn Phi Đính, 1991. Đặc điểm sinh học của cá nục sồ Decapterus maruadsi vùng biển Việt Nam. Hội nghị khoa học toàn quốc về biển lần thứ III, Tuyển tập báo cáo khoa học, Tập 1 , Sinh học và công nghệ sinh học biển, sinh thái môi trường biển. Tr. 36-45. 


\title{
BIOLOGICAL CHARACTERISTICS OF ROUND SCAD DECAPTERUS MARUADSI (TEMMINCK \& SCHLEGEL, 1843) IN THE TONKIN GULF
}

\section{Hoang Ngoc Son, Vu Viet Ha}

Research Institute for Marine Fisheries-Ministry of Agriculture and Rural Development

\begin{abstract}
Biological characteristics of the round scad Decapterus maruadsi (Temminck \& Schlegel, 1843) were analyzed using data collected by Vietnam - China Corporation Survey Project for the Marine Fisheries Resources Assessment in the Common Fishing Zone in the Gulf of Tonkin. Biological samples were monthly and randomly collected from the catches of trawl fisheries in Cat Ba island (Hai Phong) and Lach Hoi, Lach Bang (Thanh Hoa province). There were a total of 7,614 individuals of round scad collected in the period from 2012 - 2013. The result showed that the fork length of fish varied in range of $45-262 \mathrm{~mm}$ with the mean length from $166-167 \mathrm{~mm}$. The Von Bertalanffy growth function of round scad was expressed as $L_{t}=283,5 \times\left(1-e^{-0,7 \times\left(t-t_{0}\right)}\right)$. Round scad spawned once a year with the spawning season extending from January to April and reaching a peak in March. The estimated length at first maturity $\left(L_{m 50}\right)$ was $160.96 \mathrm{~mm}$ for female and $161.37 \mathrm{~mm}$ for male.
\end{abstract}

Keywords: Decapterus maruadsi, round scad, Tonkin Gulf, Von Bertalanffy growth function, length frequency, spawning season. 